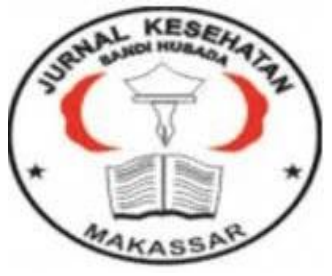

Jurnal Ilmiah Kesehatan Sandi Husada

hhttps://akper-sandikarsa.e-journal.id/JIKSH

Volume 9, Nomor 2, Desember 2020, pp 842-847

p-ISSN: 2354-6093 dan e-ISSN: 2654-4563

DOI: $10.35816 /$ jiskh.v10i2.412

\title{
Literature Review \\ Indeks Massa Tubuh Pra-Hamil Sebagai Faktor Risiko Terjadinya Bayi Berat Lahir Rendah
}

Body Mass Index Pre-Pregnancy as Risk Factor for the Incidence of Infant with Low Birth weight

Zulia Yasminanindita Fahmi

Pendidikan Dokter, Fakultas Kedokteran Universitas Lampung

Artikel info

Artikel history:

Received; Agustus 2020

Revised;September 2020

Accepted;September2020

\begin{abstract}
Abstrak
Latar belakang: Bayi dengan berat lahir rendah $(<2500$ gram) menjadi salah satu faktor utama yang dapat mempengaruhi kematian neonatal, kematian postneonatal, dan morbiditas pada anak di negara maju dan berkembang. Salah satu hal yang berpengaruh terhadap kualitas hidup bayi sejak hari pertama sampai usia dua tahun bayi adalah status gizi ibu. Status gizi ibu menunjukkan kualitas dan kuantitas pemenuhan asupan nutrisi sehari-hari dan ditentukan dengan mengukur indeks massa tubuh prahamil. Metode: menggunakan literature review dengan cara meringkas dan menggabungkan hasil yang disajikan dalam artikel. Hasil: ibu dengan indeks massa tubuh normal dan tidak normal berisiko melahirkan bayi dengan berat lahir rendah. Kesimpulan: Indeks massa tubuh pra-hamil sebagai faktor risiko terjadinya bayi dengan berat lahir rendah.
\end{abstract}

\begin{abstract}
Backgrounds: Infant with low birth weight (2500 gram) become a major factor that influence neonatal death, postneonatal death, and morbidity in both developed and developing countries. One thing that influence the quality of infant's life since day one until two years old is mother's nutritional status. Mother's nutritional status shows the quality and quantity of nutritional intake fulfillment and determine it by measuring pre-pregnancy body mass index. Methods: using literature review by summarizing and comparing the result presented in the article. Result: mothers both normal and abnormal body mass index risk deliver infant with low birth weight. Conclusion: prepregnancy body mass index as rsikfactor for the incidence of infant with low birth weight.
\end{abstract}




\begin{tabular}{lr}
\hline Keywords: & Coresponden author: \\
Status gizi ibu; & Email: zuliayasminaninditafahmi.113@gmail.com \\
IMT; & artikel dengan akses terbuka dibawah lisensi CC BY 4.0 \\
BBLR; & \\
\hline
\end{tabular}

\section{Pendahuluan}

Kehamilan adalah suatu masa penting bagi kehidupan seorang ibu, dimana pada masa tersebut ibu harus mempersiapkan diri untuk menyambut kelahiran bayinya. Ibu yang sehat dapat melahirkan bayi yang sehat dan sempurna dengan berat badan yang cukup. Pada masa ini, status gizi ibu sangat berpengaruh terhadap status gizi bayi. Janin membutuhkan energi dari ibu yang disalurkan melalui tali pusat agar tumbuh dan kembang terjadi secara optimal selama masa kehamilan (Nurhayati dan Fikawati, 2015).

Salah satu faktor utama yang dapat mempengaruhi kematian neonatal, kematian postneonatal, dan morbiditas pada anak di negara maju dan berkembang adalah bayi dengan berat lahir rendah (<2500 gram) (Fajriana dan Buanasita, 2017). Bayi yang lahir dengan berat 1500-1999 gram berisiko 8,1 kali lebih besar mengalami kematian, sedangkan bayi yang lahir dengan berat 2000-2499 gram berisiko 2,8 kali lebih besar mengalami kematian pada neonatal dibandingkan dengan bayi yang lahir dengan berat badan normal (> 2499 gram) (Kamilia, 2019). Penyebab bayi dengan berat lahir rendah (BBLR) antara lain kelahiran prematur ( $<37$ minggu), bayi Kecil Massa Kehamilan (KMK), dan kombinasi keduanya (Depkes, 2008). BBLR terbagi menjadi dua kategori, yaitu BBLR karena prematur dan BBLR karena Intrauterine Growth Retardation (IUGR), yaitu bayi yang lahir cukup bulan namun berat badan kurang. Hal-hal yang menyebabkan terjadinya BBLR dan IUGR di negara berkembang adalah karena status gizi ibu buruk, anemia, malaria, dan menderita penyakit menular seksual (PMS) sebelum konsepsi atau saat kehamilan (Asih, 2014). Dibandingkan dengan bayi dengan berat lahir normal (BBLN), BBLR berisiko 40x lebih tinggi untuk mengalami kematian pada empat minggu pertama kehidupan dan kemungkinan mengalami komplikasi neuro developmental dan kelainan kongenital lebih tinggi (Zuhairini, dkk., 2016).

Status gizi ibu hamil berhubungan erat dengan kejadian BBLR. Untuk mengetahui status gizi ibu hamil perlu dilakukan pengukuran antopometri, salah satunya adalah indeks massa tubuh (IMT). Ibu hamil yang memiliki IMT $<18,5$ memiliki risiko yang sangat tinggi terhadap bayi yang akan dilahirkan (Singarimbun, dkk., 2019). Perhitungan IMT adalah membagi berat badan dalam kilogram dengan tinggi badan dalam meter kuadrat. IMT tidak berhubungan dengan jenis kelamin, berlaku pada usia dewasa ( $>18$ tahun), dan tidak sedang hamil. Karena pada massa kehamilan terjadi peningkatan berat badan pada ibu, maka IMT yang digunakan sebagai pedoman status gizi ibu hamil adalah IMT pra hamil (Ningrum dan Cahyaningrum, 2018).

World Health Organization (WHO) mengklasifikasikan IMT menjadi underweight, normal, overweight, dan obesitas. Dikatakan underweight apabila IMT $<18,5$, praobes apabila IMT 25-29,9, dan obesitas apabila IMT >30 (Andini, 2019). Hasil survei WHO pada tahun 2012 menyatakan bahwa 15-20\% bayi di dunia lahir dengan berat rendah. Lebih dari 20 juta bayi di dunia mengalami BBLR sebanyak 15,5\%, dimana 95,6\% berada di negara yang berkembang (Zuhairini, dkk., 2016). Prevalensi terjadinya BBLR di Indonesia menurut Balitbangkes (2013) pada tahun 2010-2013 cenderung menurun, yaitu dari 11, 1\% menjadi 10,2\%. Berdasarkan latar belakang di atas, penulis tertarik membahas indeks massa tubuh pra-hamil sebagai faktor risiko terjadinya bayi berat lahir rendah. 


\section{Metode}

Metode yang digunakan adalah literature review yang bertujuan untuk menambah pemahaman tentang topik yang dibahas dengan cara meringkas topik dari berbagai jurnal nasional. Pencarian sumber yang digunakan yaitu google scholar. Pada tahap awal pencarian artikel jurnal diperoleh 3120 artikel dari tahun 2012-2020., menggunakan kata kunci "Indeks Massa Tubuh Ibu" dan "BBLR". Dari jumlah tersebut, hanya sekitar 11 artikel yang dianggap relevan. Penulis mencari, menggabungkan, menyajikan kembali materi yang diterbitkan sebelumnya, dan membandingkan hasil yang disajikan dalam artikel.

\section{Hasil Dan Pembahasan}

Hasil penelitian yang dilakukan oleh Endah dkk. (2017) dalam Hubungan Indeks Massa Tubuh Ibu dengan Kejadian Bayi Berat Lahir Rendah di RSUD Wonosiri Gunungkidul dengan melakukan pengukuran terhadap IMT ibu dengan kejadian BBLR adalah digambarkan dalam tabel 1 sebagai berikut:

Tabel 1. Hubungan Indeks Massa Tubuh Ibu dengan Kejadian Bayi Berat Lahir Rendah di RSUD Wonosari

\begin{tabular}{|c|c|c|c|c|c|c|c|c|}
\hline \multirow[t]{3}{*}{ IMT Ibu } & \multicolumn{4}{|c|}{ Kejadian BBLR } & \multirow[t]{3}{*}{$p$-value } & \multirow[t]{3}{*}{ OR } & \multirow[t]{3}{*}{$\mathrm{X}^{2}$} & \multirow[t]{3}{*}{ CI 95\% } \\
\hline & \multicolumn{2}{|c|}{ BBLR } & \multicolumn{2}{|c|}{ Tidak BBLR } & & & & \\
\hline & $\mathrm{n}$ & $\%$ & $\mathrm{n}$ & $\%$ & & & & \\
\hline Berisiko & 64 & 39,3 & 34 & 20,9 & 0,000 & 2,453 & 13,131 & $1,500-$ \\
\hline Tidak & 99 & 60,7 & 129 & 79,1 & & & & 4,010 \\
\hline
\end{tabular}

\section{Sumber: Data primer}

Interpretasi dari hasil penelitian yang telah dilakukan adalah dengan melihat nilai $p$-value 0,000 yang diartikan terdapat hubungan signifikan antara IMT ibu dengan kejadian BBLR. Didapatkan odd ratio (OR) sebesar 2,453 yang berarti ibu yang memiliki IMT berisiko berpeluang 2,4 kali lebih besar melahirkan bayi BBLR dibandingkan dengan ibu yang memiliki IMT tidak berisiko. Memiliki nilai koefisien kontingensi (C) sebesar 0,1967 berarti memiliki keeratan hubungan yang sangat rendah antara IMT ibu dengan kejadian BBLR. Selain itu digambarkan pula tentang sebaran proporsi BBLR lebih tinggi pada ibu dengan IMT berisiko $\left(<18,5 \mathrm{~kg} / \mathrm{m}^{2}\right)$ dibanding ibu degan IMT tidak berisiko $\left(>18,5 \mathrm{~kg} / \mathrm{m}^{2}\right)$. Endah dkk. (2017) menyatakan bahwa penyebab adanya ibu dengan IMT berisiko yang melahirkan bayi tidak BBLR adalah upaya menyeimbangkan kehamilan dengan kenaikan berat badan yang normal dan mengatur asupan nutrisi yang sesuai untuk tumbuh kembang janin selama masa kehamilan. Adanya ibu dengan IMT tidak berisiko namun melahirkan bayi BBLR dapat disebabkan oleh berbagai faktor, seperti ibu anemia pada trimester 3 atau hamil dalam usia dan kehamilan yang berisiko. Selain itu dapat disebabkan oleh faktor lain, seperti kebiasaan merokok atau terpaparnya asap rokok pada ibu, jenis kelamin bayi baru lahir, status sosial ekonomi dan pernikahan, pendidikan, dan gizi ibu hamil (kenaikan berat badan dan lingkar lengan atas) (Waryana, 2010).

Penelitian dengan variabel yang sama juga dilakukan oleh Asih (2014) dalam Indeks Massa Tubuh (IMT) pada Kejadian BBLR di RSUD Pringsewu Lampung dengan hasil analisis univariat terhadap distribusi IMT ibu dan distribusi kejadian BBLR serta hasil analisis bivariat kedua variabel tersebut dapat digambarkan dalam tabel 2, 3, dan 4 sebagai berikut: 
Tabel 2. Analisis Univariat Distribusi IMT Ibu dan Distribusi Kejadian BBLR

\begin{tabular}{|l|c|c|c|c|c|}
\hline \multicolumn{1}{|c|}{ IMT Ibu } & $\mathrm{f}$ & $\%$ & Kejadian & $\mathrm{f}$ & $\%$ \\
\hline $\begin{array}{l}\text { Tidak } \\
\text { normal }\end{array}$ & 68 & 34 & BBLR & 100 & 50 \\
\hline Normal & 132 & 66 & Tidak BBLR & 100 & 50 \\
\hline Jumlah & 200 & 100 & Jumlah & 200 & 100 \\
\hline
\end{tabular}

Sumber: Data primer

Tabel 3.Analisis Bivariat Hubungan Indeks Massa Tubuh dengan Kejadian BBLR

\begin{tabular}{|c|c|c|c|c|}
\hline \multirow{2}{*}{ IMT } & \multicolumn{2}{|c|}{ BBLR } & \multicolumn{2}{c|}{ Tidak BBLR } \\
\cline { 2 - 5 } & $\mathrm{f}$ & $\%$ & $\mathrm{f}$ & $\%$ \\
\hline Tidak normal & 55 & 55 & 13 & 13 \\
\hline Normal & 45 & 45 & 87 & 87 \\
\hline Jumlah & 100 & 100 & 100 & 100 \\
\hline $\mathrm{pV}=0,0001,0 \mathrm{O}=8,17,95 \% \mathrm{CI}=4,04-16,52$ \\
\hline
\end{tabular}

\section{Sumber: Data primer}

Hasil penelitian menunjukkan bahwa terdapat 34\% ibu yang memiliki IMT tidak normal $(<18,5$ dan $>29)$ dan 66\% ibu yang memiliki IMT normal (18,5-29). Jika diinterpretasikan, maka didapatkan hubungan signifikan antara IMT dengan kejadian BBLR ( $p$ value $=0,0001$ ). Odd ratio (OR) sebesar 8,17 menunjukkan bahwa ibu yang memiliki IMT tidak normal berpeluang melahirkan bayi BBLR 8,17 kali lebih tinggi dibanding dengan ibu yang memiliki IMT normal. Pada penelitian yang telah dilakukan dari 68 responden yang memiliki IMT tidak normal $(<18,5$ atau $>25,5)$ terdapat 13 responden yang melahirkan bayi tidak BBLR. Hal ini mungkin terjadi akibat kurang akuratnya pengukuran tinggi dan berat badan sehingga terjadi kekeliruan pada hasil perhitungan IMT ibu prahamil. Hal lain yang mungkin berperan sehingga responden dengan IMT tidak normal dapat melahirkan bayi tidak BBLR adalah dengan melakuan berbagai usaha untuk melindungi diri dan bayinya, misal seperti melakukan antenatal care (ANC) dengan teratur dan menjaga asupan nutrisi selama masa kehamilan.

Jika dilihat dari 132 responden yang memiliki IMT normal, 45 diantaranya melahirkan bayi BBLR. Hal ini bisa saja terjadi karena adanya kenaikan berat badan selama kehamilan, beban kerja yang tinggi, kondisi psikologis ibu selama kehamilan, dan berbagai faktor lain yang mendukung. Kedua penelitian tersebut menyatakan bahwa IMT memiliki peranan dalam kejadian BBLR. Indeks massa tubuh adalah salah satu cara untuk menentukan status gizi seseorang. Dikatakan normal atau tidak berisiko apabila IMT $>18,5-25,5$ dan tidak normal atau berisiko apabila IMT $<18,5$ atau $>25,5$. Status gizi kurang menggambarkan adanya kekurangan gizi secara kronis sebelum terjadi kehamilan, sehingga kebutuhan gizi yang dibutuhkan oleh janin selama masa kehamilan berkurang. Status gizi kurang dihubungkan dengan status sosial ekonomi keluarga, dimana keluarga dengan ekonomi rendah menjadi salah satu fakor penyebab menurunnya daya beli pangan untuk memenuhi kebutuhan sehingga mempengaruhi kualitas dan kuantitas makanan yang dikonsumsi oleh seluruh anggota keluarga (Ratnasari, dkk., 2015).

Status gizi ibu hamil sangat penting karena dapat menunjukkan kesejahteraan ibu dan janin. Ibu yang sehat akan melahirkan bayi yang sehat, begitu pula ibu yang kekurangan gizi berisiko melahirkan bayi yang kekurangan gizi. Status gizi ibu menjadi faktor utama penentu kualitas hidup bayi yang dilahirkan sejak hari pertama sampai usia dua tahun (Ariyani, 2012). Status gizi ibu hamil dapat ditentukan dengan kenaikan berat badan 
selama kehamilan. Jika seorang ibu hamil mengalami kenaikan berat badan yang normal, maka dapat dinyatakan bahwa tercukupinya asupan nutrisi yang dibutuhkan untuk tumbuh kembang janin. Adanya kenaikan berat badan selama kehamilan disebabkan oleh peningkatan ukuran berbagai jaringan reproduksi, terbentuknya cadangan lemak tubuh ibu, pertumbuhan janin, serta perubahan metabolik (Ratnasari, dkk., 2015).

\section{Simpulan Dan Saran}

Dari kedua penelitian yang telah dilakukan, maka dapat disimpulkan bahwa IMT pra-hamil menjadi salah satu faktor terjadinya BBLR, karena terdapatnya hubungan signifikan antara kedua variabel dengan $p$-value $<0,000$, serta keeratan hubungan yang sangat rendah $(C=0,1967)$. Besar risiko terjadinya BBLR pada ibu yang IMT tidak normal atau berisiko adalah 2,4 kali dan 8,17 kali lebih besar dibanding dengan ibu yang IMT normal atau tidak berisiko. Diharapkan baik ibu dengan IMT normal atau tidak berisiko maupun ibu dengan IMT tidak normal atau berisiko untuk tetap memperhatikan asupan nutrisi sejak sebelum hamil dan melakukan upaya pencegahan terjadinya BBLR, salah satunya dengan rutin melakukan antenatal care (ANC).

\section{Daftar Rujukan}

Andini, R. (2019). Indeks Massa Tubuh Sebagai Faktor Risiko Pada Gangguan Muskuloskeletal. Jurnal Ilmiah Kesehatan Sandi Husada, 10(2), 316-320. DOI: $10.35816 /$ jiskh.v10i2.178.

Ariyani, Eva, D., Achadi, E.L., \& Irawati, A. (2012). Validitas Lingkar Lengan Atas Mendeteksi Risiko Kekurangan Energi Kronis pada Wanita Indonesia. Kesma: Nasional Public Health, 7(2), 83-90.

Asih, Y. (2014). Indeks Masa Tubuh (IMT) pada Kejadian BBLR di RSUD Pringsewu Lampung. Jurnal Keperawatan, 10(1), 70-74.

Balitbangkes. (2013). Riset Kesehatan Dasar (Riskesdas). Jakarta: Balitbangkes.

Departemen Kesehatan Republik Indonesia. (2008). Modul Manajemen Bayi Berat Lahir Rendah (BBLR) untuk Bidan di Desa. Jakarta: Direktorat Jenderal Bina Kesehatan Masyarakat.

Endah, M.F., Theresia, M., \& Wahyuningsih, H.P. 2017. Hubungan Indeks Massa Tubuh Ibu dengan Kejadian Bayi Berat Lahir Rendah di RSUD Wonosiri Gunungkidul. Jurnal Keperawatan, 11(1), 8-15.

Fajriana, A., \& Annas, B. (2018). Faktor Risiko yang Berhubungan dengan Kejadian Bayi Berat Lahir Rendah di Kecamatan Semampir Surabaya. Media Gizi Indonesia, 13(1), 71-80. DOI: 10.20473/mgi.v13i1.71-80.

Kamilia, A. (2019). Berat Badan Lahir Rendah dengan Kejadian Stunting pada Anak. Jurnal Ilmiah Kesehatan Sandi Husada, 10(2), 312-315.

Ningrum, E.W., \& Cahyaningrum, E.D. (2018). Status Gizi Pra Hamil Berpengaruh terhadap Berat dan Panjang Badan Bayi Lahir. MEDISAINS: Jurnal Ilmiah Ilmu-ilmu Kesehatan. 16(2), 89-94.

Nurhayati, E., \& Fikawati, S. (2015). Indeks Massa Tubuh (IMT) Pra Hamil dan Kenaikan Berat Badan Ibu Selama Hamil Berhubungan dengan Berat Badan Bayi Lahir. Journal Ners and Midwifery Indonesia, 4(1), 1-5.

Ratnasari, D., Suhartono, \& Rahfiludin, M.Z. (2015). Faktor Risiko Kejadian Berat Badan Lahir Rendah di Area Pertanian (Studi di Kabupaten Brebes). J. Gizi Pangan, 12(1), 41-48. DOI: $10.25182 /$ jgp.2017.12.1.41-48.

Singarimbun, A.S., Kareri D.G., \& Sagita, S. (2019). Hubungan Lingkar Lengan Atas, Indeks 
Masa Tubuh, dan Tekanan Darah Ibu Hamil dengan Bayi Berat Lahir Rendah di Puskesmas Bakunase Kota Kupang. Cendana Medical Journal. 16(1), 125-131. http://dx.doi.org/10.21927/jnki.2016.4(1).1-5.

Waryana. (2010). Gizi Reproduksi. Yogyakarta: Pustaka Rihanna.

Zuhairini, Y., Kasmanto, H., \& Nugraha, G.I. (2016). Indeks Masa Tubuh Awal Kehmilan sebagai Indikator yang Paling Berperan terhadap Kenaikan Berat Badan Ibu. MKB, 48(3), 171-175. http://dx.doi.org/10.15395/mkb.v48n3.847. 